\title{
Inti Raymi ehk päikesepüha - Kolumbuse-eelse Peruu inkade suurimaid usupühi
}

Inkade Inti Raymi pidustuste parim kirjeldus pärineb 16. sajandi hispaania kroonikult ja katoliku vaimulikult Inca Garcilaso de la Vegalt, kes oli ema poolt suguluses inkade valitsejasooga. Järgnevalt tutvume, kuidas peeti seda püha umbes 500 aastat tagasi ja mida tähendasid mõned seal läbiviidud riitused. ${ }^{1}$

Sõna Raymi tähendab ketšua keeles pidustust, Inti aga päikest. Neljast usupühast, mida inka keisrid Tahuantinsuyu (Nelja Ilmakaare riigi) pealinnas Cuzcos (Maailma Naba linnas) pühitsesid, oli tähtsaim Inti Raymi, mida peeti juunis ja mis oli pühendatud päikesejumal Intile. ${ }^{2}$

Inti Raymist võtsid osa kõik curacad (alistatud rahvaste pealikud), sõjapealikud, ülikud ja teised kõrgest soost isikud kogu riigist. Kellel ei olnud võimalik tulla Cuzcosse, saatis sinna oma poja või mõne teise tähtsa esindaja. Kindlasti juhatas pidustusi inkade keiser, kui ta parajasti sõjakäigul ei olnud.

Esimesed tseremooniad viis Inka kui kõrgeim preester läbi ise, kuigi tema onu või siis noorem vend oli riigi ametlik ülempreester. Nimelt peeti Inkat päikesejumala pojaks, tema tiitel oli Päikese Poeg ja kes muu kui mitte tema pidi suurimat päikesepidustust juhatama. Provintside ja piirkondade ülemad kandsid kulla ja hõbedaga kaunistatud rõivaid, veidi madalamatel ülikutel olid üll jaaguarinahad, neid ehtisid kondoritiivad või fantastilised maskid. Protsessioonis osalesid pillimängijad, sõjamehed kandsid täisrelvastust, ohvitserid aumärke ja võimutunnuseid.

Pidustusele eelnes kolmepäevane paastuaeg, mil kogu riigis olid kõik tuled kustutatud. Viimasel ööl valmistasid preestrid ette ohvriloomad (laamad, alpakad ja vikunjad) ning päikesele pühitsetud road ja joogid. Päikesele pühitsetud neitsid olid oma kloostrites küpsetanud hiigelhulga ümmargusi maisikakukesi ja pruulinud püha maisijooki chichat. Seda kõike tegid preestrid ja päikeseneitsid erakordselt hoolikalt (Garcilaso de la Vega 1988: VI rmt, 20. ptk).

http://haldjas.folklore.ee/tagused/nr24/kulmar.pdf 


\section{Tarmo Kulmar}

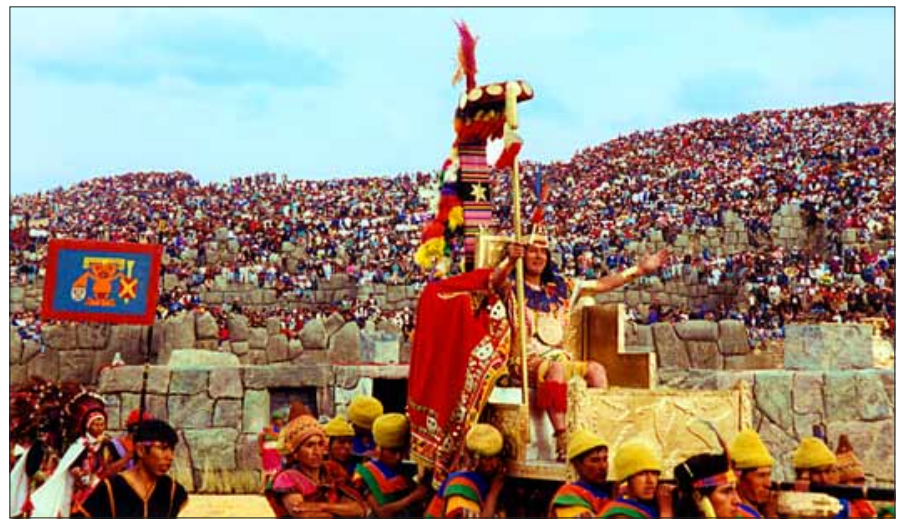

Foto 1. Inti Raymi algas talvisel pööripäeval (Peruu asub lõunapoolkeral ja seetõttu on seal talv meie suvekuudel). Praegu korraldatakse seda pidustust ühepäevase rahvuspühana 24. juunil. Selleks puhuks saabub Cuzcosse ka Peruu kõrgeim juhtkond, et oma maa kunagisele hiilgavale minevikule austust avaldada. Inti Raymile eelneval ööl leiavad Cuzcos aset tundidepikkune lõbus rongkäik ja rahvapidustused. Inti Raymil osaleb ainsal korral aastas avalikkuse ees kui Inka ka muistse keisridünastia seaduslik järeltulija, kes muul ajal töötab arstina Foto Tarmo Kulmar 1996.

Kui kõik tarvilik oli valmis seatud, ilmus inkade keiser kogu oma saatjaskonnaga pidupäeva koidikuvalguses ootava rahva ette. Kõik liikusid rongkäigus vastavalt vanusele ja positsioonile. Nii saabusid nad Cuzco peaväljakule Haukay patale (Relvade väljakule), kus ootasid koos päikesetõusu. Kõik seisid paljajalu ja silmitsesid pingsalt idakaart. Kui päike tõusis, kummardusid nad sügavalt ettepoole (see tähendas neil sama, mis meil põlvitamine), et tervitades palvetada. Nad sirutasid käed välja, tõstsid need näo kõrgusele ja suudlesid õhku. Nii näitasid nad päikesele armastust ja tänulikkust, sest pidasid päikest oma jumalaks ja lausa lihaseks isaks.

Curacad, kes ju keiserlikku suguvõsasse ei kuulunud, kogunesid kõrvalasuvale Cusi patale (Rõõmu väljakule). Nad austasid päikest samal kombel nagu inkadki. Siis tõusis Inka, kuna teised jäid veel kummardusse. Ta haaras kaks suurt kuldpeekrit, nn aquillat, mis olid täidetud püha joovastava joogiga. Järgneva tseremoonia viis ta läbi kui esmasündinu oma isa, päikesejumala nimel. Paremas käes 


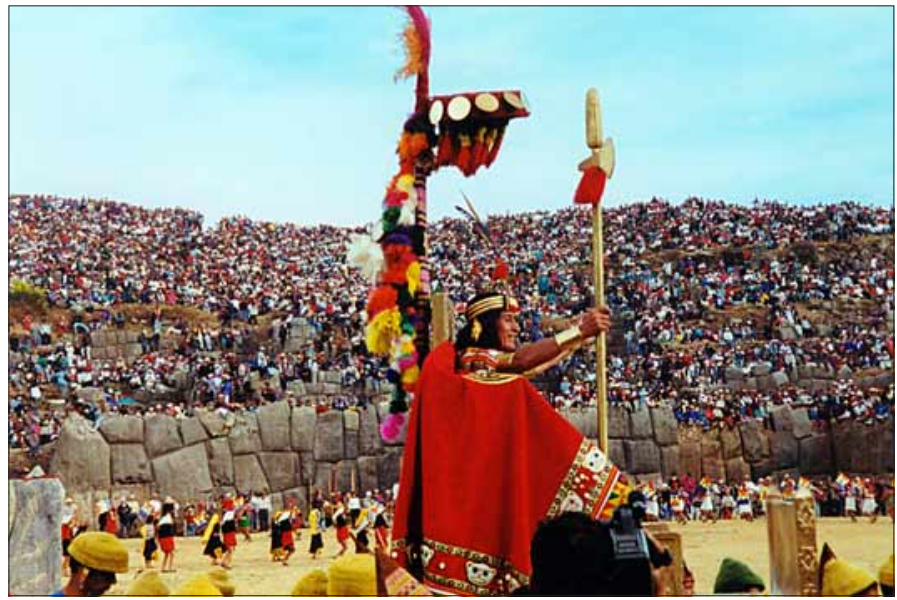

Foto 2. Kirjutise autoril oli õnn 1996. aastal isiklikult Inti Raymil viibida ja Inkat lähedalt pildistada. Foto Tarmo Kulmar 1996.

oleva peekri tõstis ta toostiks päikese terviseks. Selle riitusega tervitas ta enda ja oma suguvõsa nimel päikest, oma esiisa.

Pärast seda sümboolset toimingut valas ta paremas käes oleva peekri tühjaks suurde kannu, otsekui oleks päike sealt joonud. Kannust voolas jook aga mööda väärismetallist toru päikesetemplisse, mis kandis nime Cori cancha (Kuldne õu). Vasakus käes olevast peekrist võttis keiser ise sõõmu ja valas siis iga oma lähikondlase kuldnõusse, mida need käes hoidsid, kuni kõrvalseisev suur jooginõu pikkamisi tühjaks sai. Seda jooki jõid toostiks ainult keiserliku suguvõsa liikmed. Curacad teisel väljakul said samasugust jooki, ainult see ei olnud pühitsetud.

Siis liikus protsessioon täielikus korras päikesetempli peasissekäiguni. Kakssada sammu enne ust võtsid kõik sandaalid jalast, välja arvatud Inka, kes võttis jalatsid ära vahetult ukse ees. Kogu keiserlik suguvõsa siirdus templisse ja sooritas seal hiiglasuure seinal rippuva kuldse päikeseketta ees oma kummardused. Curacad, kes pühasse hoonesse siseneda ei tohtinud, sest nad ei olnud päikesejumala sugulased, jäid templiesisele väljakule.

Inka annetas ohvriks mõlemad kuldpeekrid, millega ta oli tseremoonia läbi viinud. Teistelt kogusid preestrid anumad kokku. See- 


\section{Tarmo Kulmar}

järel läksid nad välja, et korjata nõud kokku ka curacade käest. Ühtlasi tõid alamad annetusi kogu riigist: kuld- ja hõbeesemeid, vääriskive, samuti väärismetallidest tehtud laamasid, alpakasid, vikunjasid, kodulinde ja -loomi, jaaguare, puumasid ja teisi metsloomi, ühesõnaga kõike, mille poolest mingi provints rikas oli. Kujud olid väga loomutruud, ainult elusuurusest väiksemad.

Kui kõik olid oma ohvriannid üle andnud, mindi üksteise järel väljakule tagasi. Siis tõid preestrid välja suure karja erivärvilisi laamasid ja alpakasid; need olid nimelt samuti igaüks ise karva, nii nagu eurooplastel hobused. Kõik need loomad olid päikesejumalale määratud. Siis võtsid nad ühe musta isaslooma, sest must oli pühim värv kõigi värvide hulgas. Ka keiser kandis pidulikul puhul musta (leinavärviks oli aga hallikaspruun). Must isasloom ohverdati selleks, et välja lugeda ettekuulutusi, kuidas pidu kulgema hakkab ja milline saatus riiki eeloleval aastal ootab (Garcilaso de la Vega 1988: VI rmt, 21. ptk).

Kui see loom oli ohverdatud, tapeti veel hulk laamasid ja alpakasid. Preestrid lõikasid loomadel kõri läbi, lasksid vere välja voolata ning eemaldasid südame ja kopsud, põletades need päikesejumala auks tuhaks.

Kõige õnnelikum märk oli see, kui väljalõigatud kopsud veel elasid, ja kui seda märgati, ei pööratud teistele, õnnetumatele märkidele enam tähelepanu. Kõige õnnetum märk oli aga see, kui tapetav laama jalule tõusis ja teda kinni hoidva preestri eemale tõukas. Sel juhul korrati ohverdamist uue laamaga. Kui enne oli sama halb, siis võeti nukrusega teadmiseks, et Isa Päike ei ole armuline ja saadab riigile eeloleval aastal julma sõja, viljaikalduse või kariloomade huku.

Kui märgid olid õnnelikud, jätkus pidu suure juubeldamisega. Nüüd läideti ohvrite põletamiseks uus tuli. Selle süütamiseks kasutati ülempreestri käevõrul olevat poleeritud vääriskivi, mille abil fokuseeriti päikesekiirte kimp puhastatud puuvillale, kuni see süttis. Selle tulega põletati ohverdatavad siseelundid ja praeti ohvriloomade liha. Päikeseneitsid viisid tule templisse ja kloostritesse ning seal valvati seda hoolega. Väga paha märk oli, kui päikesekiirte abil süütamine ebaõnnestus ja tule pidi läitma tulekiviga.

Ohvriliha küpsetati mõlemal väljakul ja jagati koos pühitsetud kakukestega kõikidele peost osavõtjatele. Alles seejärel toodi anumad pühitsetud joogiga, sest Peruu indiaanlased ei joo söömise ajal. Jooki tarvitati suures koguses, ent tuleb märkida, et end täiesti 
purju juua oli suur häbi. Nõnda on see indiaanlaste juures praegugi (Garcilaso de la Vega 1988: VI rmt, 22. ptk).

Lehtkullast kandetoolis istuv keiser saatis nüüd oma hõimlased enda nimel Tahuantinsuyu kõikide rahvaste auks tooste ütlema ja nende saadikutega kokku jooma. Selleks toostiks oli tarvitusel alati kaks ühesuurust peekrit. Jooma kutsuja hoidis kätes mõlemat peekrit, ulatas ühe sellele, kellele ta kokkujoomiseks ettepaneku tegi, ja ütles: "Sapa Inca [Ainus Inka] teeb sulle ettepaneku minuga kokku juua ja mina tulin tema nimel seda sinuga tegema." See, kellele ettepanek tehti, võttis anuma suure aupaklikkusega vastu, vaatas päikese poole, suudles õhku ja andis peekri pärast tühjendamist sõnatu tänuga keisri esindajale tagasi.

Siis kutsus Inka ülikuid ja pealikuid endaga kokku jooma. See oli alamate toost Inka enda auks. Kõigepealt tulid vaprad väepealikud, seejärel Cuzco piirkonna ülemad, siis inkade aristokraatia teised liikmed ja curacad. Rongkäigus tulid nad keisri juurde ja pakkusid sõnatult oma peekreid kokkujoomiseks. Loomulikult ei pidanud Inka neid kõiki tühjendama, ta tõstis anumad lihtsalt huultele ja rüüpas harva pisilonksu suure armulikkuse märgiks. Siis andis ta nõu oma kaaskondlase kätte, et need Inka nimel ja tema terviseks toostipartneriga kokku jooksid. Lõpuks tagastati jooginõu alamale. Neid anumaid, mida Inka oma käe või huultega oli puudatanud, säilitati kui reliikviaid.

Pärast ametlikke toostide vahetamisi läksid kõik oma kohtadele. Algasid tantsud, laulud ja muud lõbustused. Sel ajal kutsusid väiksemad ülikud üksteist pidevalt tooste vahetama.

Inti Raymi kestis söömise, joomise ja tantsudega kümme päeva, misjärel läksid külalised täis rõõmu ja tänumeelt koju tagasi.

Kui keiser viibis sõjakäigul või ringsõidul, peeti ametlikku Inti Raymit seal, kus ta parajasti resideeris, ainult väiksema pidulikkusega. Ometi leidis pidu aset ka Cuzcos, kus seda juhtis päikesetempli ülempreester (Garcilaso de la Vega 1988: VI rmt, 23. ptk).

Teised hispaania kroonikud lisavad sellele põhjalikule kirjeldusele võrdlemisi vähe juurde. José de Acosta kinnitab Garcilaso de la Vega informatsiooni uusi andmeid sisuliselt juurde lisamata (Acosta 1991: 25. ptk). Francisco de Avila Inti Raymit ei kirjelda (vt Avila 1939). Bernabé Cobo teatab, et Inti Raymi ajal sooritasid paljud Tahuantinsuyu elanikud palverännakuid Cuzcosse, ja kirjeldab, kui rikkalikult olid kõik osavõtjad rõivastatud ja ehitud, ning lõpuks märgib, kui palju koduloomi ja mil viisil ohvriks toodi. Näi- 


\section{Tarmo Kulmar}

teks esimesel päeval oli ohverdatud sada laamat (Cobo 1893: IV rmt, 28. ptk). Juan de Betánzos kinnitab, et Inti Raymi ja ka teised suurpühad oli 15. sajandi keskel seadnud sisse keiser Inca Pachacutek Yupanqui (Betánzos 1987: 14. ptk).

Kolm kroonikut seevastu edastavad erakordselt huvitavat lisateavet. Nimelt teatavad nad inkade toodud inimohvritest. Pedro de Cieza de León, üsna objektiivne katoliku vaimulik, märgib oma Cuzco linna kirjelduses põgusalt, et päikesetempli kõrval asetses hoone ohverdatavate valgete loomade ning ohvriks toodavate laste ja täiskasvanute tarbeks (Cieza de León 1987: 93. ptk). Pedro de Sarmiento de Gamboa kirjutab inimohvrist capac cochast, mille käigus mõned 5-6-aastased lapsed koos kuld-ja hõbeesemetega elusalt maeti. Capac cochat toimetati väga harva (Sarmiento de Gamboa 1942: 31. ptk). Felipe Guamán Poma de Ayala jutustab capac cocha ohvrist juba seoses Inti Raymi kirjeldamisega: viissada süütut last, kes olid koka või teiste narkootiliste ainetega uimastatud, maeti elusalt Inti Raymi käigus ülijumal Wiracocha ja päikesejumal Inti auks koos suure hulga kuld- ja hõbeesemetega (enterrauan a los niños ynosentes quinientos y mucho oro y plata) (Poma de Ayala 1980: 221).

Inimohvri küsimus inkade religioonis on võrdlemisi problemaatiline. Inimeste ohverdamine ise ei ole inkade puhul enam diskussiooniobjekt. Enamik autoreid on seisukohal, et capac cocha rituaal oli olemas, ent seda toimetati erakordselt harva. Hermann Trimborn näitab, et inimesi toodi ohvriks vaid suurte õnnetuste ja hädade puhul (näljahäda, ikaldus, taud), aga ka vana keisri surma ja uue valitseja troonileastumise korral. Ohvreiks toodi lapsi ja neitseid, kes surmati kägistades. Ta arvab ka, et nende hulk oli üsna väike (Trimborn 1969). Heinrich Cunow ja Hans Disselhoff toetavad seevastu seisukohta, et ohverdatavate hulk oli siiski suur (Cunow 1937; Disselhoff 1972).

Ometi võib arvata, et ohverdatavaid ei olnud väga palju, kindlasti mitte nii palju nagu muistses Mehhikos. Inkad olid praktiliselt mõtlevad, pragmaatilised valitsejad ja neil oli kaugele välja arendatud asendusohvri süsteem. Kuulus Peruu ajaloolane Luis Varcárcel toonitab, et paljud kroonikud ei ole ajaloolisi fakte õigesti seletanud, sest nad ei ole hästi mõistnud ketšua keelt. L. Varcárcel näitab, et üks kroonikutest, Las Casas, kirjutab Inti Raymi puhul, et 200 neitsit on ohverdanud chicha-jooki, et on ohverdatud sadu laamasid, aga inimohvrit ta sealjuures ei maini (Varcárcel 1964). 
Tänapäeval on tuntud uurijad avaldanud vanade peruulaste inimohverdamise kohta mitmeid huvitavaid käsitlusi. Antje Kelm on seisukohal, et ohverdatavate arv oli väike (Kelm 1990). Hanns Prem leiab, et religioossete aastapidustuste puhul, aga ka poliitilistel põhjustel toodi ohvriks väga vähe lapsi (Prem 1989). Waldemar Espinoza Soriano arvab, et inimohver kujutas endast sotsiaalse kontrolli institutsiooni, mille juures oli ohverdatud ainult kuni 10-aastaseid poisslapsi ja ainult allutatud hõimudest (Espinoza Soriano 1990). Federico Kauffmann-Doig kirjutab, et capac cochat sooritati kui erakordset ohvritalitust eelkõige maa viljakuse tagamiseks (Kauffmann-Doig 1991). Pierre Duviols on näidanud, et ohverdamiskord, rituaalid ja sealjuures aset leidvad protsessioonid olid palju tähtsamad kui ohverdatavate hulk (Duviols 1976). Seda toetavad ka Antje Kelm ja Antonio del Busto Duthurburu (Kelm 1990: 530; Busto Duthurburu 1981: 302).

Tuleb arvestada ka tõigaga, et kroonik Felipe Guamán Poma de Ayala ei olnud ketšua, vaid pärines ühe Põhja-Peruus elava inkade alistatud rahva hulgast. See tähendab, et ta kirjeldas ilmselt inkade kui anastajate kombeid mitte just kõige objektiivsemalt. Seetõttu võime mõneti rohkem usaldada kroonik Inca Garcilaso de la Vegat, kes oma põhjalikus ja ammendavas kroonikas inimohvrist seoses Inti Raymi pühaga midagi ei jutusta. Teisalt peame arvestama sellega, et Garcilaso de la Vega oli ise pooleldi inka, kes võis üht-teist maha vaikides püüda oma rahvast Hispaania riigivõimu ja inkvisitsiooni terrori eest kaitsta. Niisiis on tõde nähtavasti kuskil vahepeal - inimohvrit inkad tõid, aga suhteliselt harva, nagu seda kinnitavad ka viimati tsiteeritud uurijate tööd.

\section{Järeldused}

1. Inti Raymi päikesepüha oli Tahuantinsuyu suurimaid üldriiklikke pühasid, millest kogu riigi ülikkond osa võttis. See tähendab, et Inti Raymi oli õieti ka inkade ametliku usundi suur palverännak pealinna - Maailma Naba linna - , kus asus tähtsaim päikesetempel Cori cancha. Selle pidustuse eesmärk oli saada keisrilt kui elavalt jumalalt õnnistust, aga ka paluda päikesejumalale ohvreid tuues eelolevaks aastaks viljakust.

2. Inkad olid religioonifenomenoloogiliselt asendusohvri tasemele jõudnud. Samaaegselt toodi nii esimese (kariloomi) kui ka teise 


\title{
Tarmo Kulmar
}

astme (ohvrijook, väärismetallesemed) asendusohvrit. Üsna tõenäoliselt esines ürgset esmaohvrit (inimeste ohverdamist) väga harva. Laialt oli kasutusel ka kommuniooniohvri komme - ühine ohvrisöömaaeg ja -joomaaeg koos Inka, päikesejumala asemikuga maa peal, see tähendab aga, et koos päikesejumala endaga. See ühine söömine ja joomine täitis samaaegselt ka poliitilist, kogu tsentraliseeritud riiki konsolideerivat rolli.

3. Ei ole sugugi vähetähtis toonitada, et oma ideoloogiliste eesmärkide, organiseerituse ja kõikehõlmavuse tõttu kujutab talvise pööripäeva püha Inti Raymi endast totalitaarse suurriigi (mida inkade Tahuantinsuyu Kolumbuse-eelses Ameerikas ka ainsana oli) religioosse massitseremoonia klassikalist näidet.

\section{Kommentaarid}

${ }^{1}$ Kirjelduses püütakse võimaluse piires säilitada kroonikateksti stiili.

${ }^{2}$ Inti Raymi algas talvisel pööripäeval (Peruu asub lõunapoolkeral ja seetõttu on seal talv meie suvekuudel). Praegu korraldatakse seda pidustust ühepäevase rahvuspühana 24. juunil. Selleks puhuks saabub Cuzcosse ka Peruu kõrgeim juhtkond, et avaldada austust oma maa kunagisele hiilgavale minevikule. Inti Raymile eelneval ööl leiavad Cuzcos aset tundidepikkune lõbus rongkäik ja rahvapidustused. Inti Raymil osaleb ainsal korral aastas avalikkuse ees ka Inka kui muistse keisridünastia seaduslik järeltulija, kes muul ajal töötab arstina. Selle kirjutise autoril oli õnn 1996. aastal isiklikult Inti Raymil viibida ja Inkat lähedalt pildistada (vt foto 1 ja 2 ).

\section{Kirjandus}

\begin{abstract}
Allikad
Acosta, José de 1991. Das Gold des Kondors: Berichte aus der Neuen Welt 1590 und Atlas zur Geschichte ihrer Entdeckung [originaal: Historia natural y moral de las Indias]. Alte abenteuerliche Reiseberichte. Rudolf Kroboth \& Peter H. Meuer (tõlk ja koost). Stuttgart-Wien: Edition Erdmann in K. Thienemanns Verlag.
\end{abstract}




\section{Tarmo Kulmar}

Avila, Francisco de 1939. Dämonen und Zauber im Inkareich. [Originaal: De priscorum Huaruchiriensium Origine]. Quellen und Forschungen zur Geschichte der Geographie und Völkerkunde 4. Hermann Trimborn (tõlk) \& Georg Friederici (sissejuh). Lepizig: K. F. Köhler Verlag.

Betánzos, Juan de 1987. Suma y Narración de los Incas. Madrid: Atlas.

Cieza de León, Pedro 1987. La crónica del Perú 3. Lima: Pontificia Universidad Católica del Perú.

Cobo, Bernabé 1893. Historia del Nuevo Mundo 4. Sevilla: Imp. de E. Rasco.

Garcilaso de la Vega, Inca 1988. Comentarios reales de los Incas 1-3. Lima: Editorial Mercurio S.A.

Poma de Ayala, Felipe Guaman 1980. El Primer Nueva Corónica y Buen Gobierno. Colección América nuestra 31: América antigua. México: Siglo Veintiuno Editores S.A.

Sarmiento de Gamboa, Pedro 1942. Historia de los Incas. Buenos Aires: Emecé Editores.

\section{Uurimused}

Busto Duthurburu, José Antonio del 1981. Perú Incaico. Lima: Librería Studium S.A.

Cunow, Heinrich 1937. Geschichte und Kultur des Inkareiches. Amsterdam: Elsevier.

Disselhoff, Hermann 1972. Das Imperium der Inka und die indianischen Frühkulturen der Andenländer. Die Welt des Wissens. Berlin: Safari-Verlag. Duviols, Pierre 1976. La Capaccocha: Mecanismo y Función del Sacrificio humano. Allpanchis 9, lk 11-57.

Espinoza Soriano, Waldemar 1990. Los Incas: Economía, sociedad y Estado en la era del Tahuantinsuyo. Lima: Amaru Editores.

Kauffmann-Doig, Federico 1991. Introducción al Perú antiguo: Una nueva perspectiva. Lima: Editorial Monterrico S.A.

Kelm, Antje 1990. Gründzüge der Religionen des Zentralen Andenraumes. Ulrich Köhler (koost). Altamerikanistik: Eine Einführung in die Hochkulturen Mittel- und Südamerikas. Ethnologische Paperbacks. Berlin: Dietrich Reimer Verlag, lk 519-533.

Prem, Hanns J. 1989. Geschichte Altamerikas. Oldenbourg-Grundriß der Geschichte 23. München: R. Oldenbourg Verlag. 


\section{Tarmo Kulmar}

Trimborn, Hermann 1969. Alte Hochkulturen Südamerikas. Die Kulturen Alt-Amerikas. Handbuch der Kulturgeschichte 2. Frankfurt am Main: Akademische Verlagsgesellschaft Athenaion.

Varcárcel, Luis Eduardo 1964. Historia del Perú antiguo. A través de la fuente escrita. Lima: Librería Editorial Juan Mejía Baca. 